\title{
Assessing Global Awareness over Short-Term Study Abroad Sequence: A Factor Analysis
}

\author{
Mark R. Kurt \\ Elon University \\ Neal H. Olitsky \\ University of Massachusetts Dartmouth

\section{Paul Geis} \\ Elon University
}

In the 2007 report, College Learning for the New Global Century, the authors highlight several changes both in the aims and in the outcomes for postsecondary education in the US for the $21^{\text {st }}$ century (Association of American Colleges, Universities, and National Leadership Council (US), 2007). The report outlines "Essential Learning Outcomes" for the development of global citizens. ${ }^{1}$ Several key outcomes include: intercultural knowledge and competence, civic knowledge and engagement, and knowledge of human cultures and the physical and natural world. Academic study abroad programs are uniquely equipped to give students the opportunities to achieve outcomes for global citizenship (Langran, Langran, and Ozment 2009). These programs take students outside the confines of their home institutions and expose students to new cultures and languages while integrating academic content to enhance the learning experience.

Due to this sharpening focus on global citizenship, the increase in participation in study abroad programs is unsurprising. In the 2009-2010 academic year, over 270,000 U.S. undergraduates chose to study outside the U.S., an increase of $88 \%$ over the past 10 years (Chow and Villarreal 2011). Of these students, more than 153,000 participated in a short-term study abroad (STSA) program (Chow and Villarreal 2011). This impressive growth both in longer term study abroad and in STSA participation is likely to continue as the current share of students who study abroad remains small in comparison to the 20.4 million current undergraduate students in the United States.

There are a variety of reasons why students choose an STSA program versus a longer program. First, these programs offer students a number of benefits similar to semester-long study abroad programs (Sachai, Brasher, and Fee 2009). These benefits include increased knowledge of the host country and its culture, exposure to different languages, and a change in a student's perceptions of world view (Lewis and Niesenbaum 2005b). Second, there are an increasing number of options in terms of location, in academic content, and in format for students to study abroad over shorter durations. The increasing variety of STSA programs makes them more appealing than both

\footnotetext{
${ }^{1}$ See Association of American Colleges, Universities, and National Leadership Council (US), 2007 for a discussion on global citizenship.
} 
traditional courses at the home institution and longer-term study abroad courses. Third, many of these short-term experiences impose fewer constraints for on-time completion of degrees; STSA programs can be completed during Winter/January terms, May terms or over the summer, easing scheduling demands for students to complete their required coursework. This increased flexibility allows more students both to participate in study abroad programs and to reap the benefits these programs confer.

Given STSA's role in facilitating essential outcomes for global citizenship, it is necessary to assess the effects of these experiences on students. The importance of assessment has intensified as the number of students participating in STSA programs and resources from undergraduate institutions committed to studying outside the United States have increased, regardless of program duration. Careful assessment is a critical tool to evaluate and improve STSA programs.

Several studies assess a wide range of outcomes resulting from study abroad experiences (Carlson and Widaman 1988; Carlson, Burn, and Yachimowicz 1990; DeLoach, et al. 2003; Ingraham and Peterson 2004; Paige et al. 2009; Ogden 2010). ${ }^{2}$ However, much of the literature highlights the positive outcomes achieved through longer-term study abroad programs. By contrast, there is less agreement regarding the outcomes of STSA programs. In general, studies find that STSA programs provide the same benefits as longer duration programs; however, the magnitude of these benefits may be muted. For instance, Dwyer (2004) finds significant differences in educational attainment, career, and intercultural awareness outcomes for students participating in full year programs versus shorter programs. ${ }^{3}$ Alternately, Jon and Fry (2009) find no effect of duration on outcomes such as educational attainment or being internationally career oriented. The debate is still on-going regarding the efficacy of STSA programs. ${ }^{4}$

A primary goal of STSA programs is to develop students' awareness of international and global issues. In Chieffo and Griffiths (2004), the authors construct a survey to provide several measures of global awareness, a concept which encompasses several content areas including knowledge of international issues, realization of personal growth and development, awareness of global interdependence, and functional knowledge. One of the contributions of Chieffo and Griffiths (2004) is the construction of a survey designed to measure global awareness and its components, which is adopted and extended in this paper.

The present study furthers our understanding of the relationship between STSA and changes in students' levels of global awareness by answering two sets of key questions. The first set, do students experience increases in their levels of global awareness through participation in a one-credit hour preparatory course taught at the home institution, through participation in a four-credit STSA course, or both? The answers to these questions have important implications. If the results indicate

${ }^{2}$ Ogden (2010) provides an excellent survey of the study abroad assessment literature.

${ }^{3}$ Dwyer (2004) does find positive effects for STSA. However, the outcomes are greater from full year programs.

${ }^{4}$ Fischer (2009) reports the lack of significant impact on long term global engagement outcomes based on the SAGE survey 
that students experience large increases in global awareness from the preparatory course, then oncampus courses may be a less expensive alternative to STSA programs while providing similar learning outcomes. Alternatively, if the preparatory course facilitates the development of skills which allow students to obtain higher levels of global awareness, then the preparatory course and the STSA program complement each other and both courses may be important to develop this awareness. Finally, the preparatory course may be a forum to provide information about the upcoming STSA program and thus has no effect on awareness. The second set of questions is whether previous experiences abroad, both academic and nonacademic, diminish the impact from the current STSA sequence on students' levels of global awareness? In other words, are there limitations to benefits from STSA offered to students who have previous experience abroad? If the benefits of an additional STSA are reduced, then the role of STSA may be recast as primarily supporting students who have little exposure abroad. Alternatively, if STSA continues to confer measureable benefits, then it suggests students with various levels of exposure abroad can expect to increase their levels of global awareness. Given the financial cost and time resources associated with STSA, the answers to this question have important ramifications. While the existing literature highlights the importance of both sets of questions (Chieffo and Griffiths 2004; Gullekson, Tucker, Coombs, and Wright 2011), to our knowledge, no existing study adequately answers them.

To answer the aforementioned questions, this paper extends the work of Chieffo and Griffiths (2004). We adopt their cross-sectional survey that assesses levels of global awareness and extend it into a longitudinal study along with adding demographics and prior experience abroad, both academic and non-academic. Students enrolled in an STSA sequence consisting of a one-credit hour preparatory course and a four-credit hour study abroad experience, are surveyed at three distinct points: prior to receiving any instruction, after a one-credit hour preparatory course but prior to the four-credit hour study abroad course, and upon return to the home institution at the conclusion of the STSA experience. We perform exploratory factor analysis on the individual survey items and generate five uncorrelated factors: general global awareness, functional knowledge, foreign media exposure, communication and culture, and foreign language exposure. Factor analysis is a data reduction technique that reduces a large number of questions into a small number of easilyinterpretable factors. This technique allows the researcher to combine several questions that measure similar characteristics and may provide a more meaningful interpretation of the results. In addition, we estimate the effects both of the preparatory course and of the STSA program to determine the association between these courses and the global awareness measures. Finally, our analysis examines the data in two ways. First, we analyze the pooled cross section, which compares the differences in means of the awareness measures between each of the three survey points. Second, we consider the matched sample which follows the same individuals over all three surveys, allowing us to control for individual characteristics.

Our results indicate that students' levels of global awareness are significantly larger after the STSA program in three of the five factors: general global awareness, functional knowledge, and foreign media exposure compared both to the initial sample and to the sample taken after the onehour preparatory course. However, levels of global awareness do not increase uniformly over the sequence; for a vast majority of the survey items and factors, participation in the one-hour preparatory course has no significant effect on students' global awareness. We find these results are 
robust, both to t-tests of means and to multivariate regression models. These results suggest several aspects of global awareness with which STSA programs have a positive association, and indicate the content areas for which STSA programs may benefit students. The strongest of these effects relate to those outcomes pertaining to functional knowledge. In addition, the results suggest that preparatory courses have no measurable effect on the global awareness outcomes during the fall semester. However, we are unable to rule out the possibility that the preparatory course has an indirect effect which helps facilitate accumulation of global awareness while abroad.

\section{Background}

Chieffo and Griffiths (2004) were the first to develop a large-scale cross-sectional assessment of global awareness through STSA experiences. The authors implemented a cross-sectional survey with over 2,300 responses at the University of Delaware for two groups of students: all students studying abroad during a winter term and all students staying on campus enrolled in a course with a significant international component. Students were surveyed at the conclusion of the winter-term course whether abroad or not. Results showed distinct differences between those students who studied abroad and those who remained at the home institution. Chieffo and Griffiths (2004) find statistically significant differences $(\mathrm{p}<.005)$ for 16 of the 21 survey questions between students who completed STSA programs and those stayed at the home institution. The authors conclude that students who study abroad for short durations develop higher levels of global awareness when compared to students who's course work includes an international component at the home institution.

Following Chieffo and Griffiths (2004), Gullekson et al. (2011) studies the effects of a businessfocused STSA experience on multiple student outcomes including those related to: global awareness, ethnocentrism, intercultural apprehension, and international activities. Their study extends Chieffo and Griffiths (2004) into a longitudinal survey, surveying students immediately prior to departure and upon return from the STSA. Gullekson, Tucker, Coombs, et al. (2011) also includes a control group of thirty students who did not go abroad. Looking at the same individual at two distinct points in time is particularly advantageous as it controls for individual differences that could be correlated with the decision to study abroad. Their results indicated that participation in STSA programs led to significant increases in students' levels of global awareness. However, they found that students who went abroad had lower levels of global awareness than students in the control group from the pre-test. The authors noted that their results may be influenced by a one-credit hour required preparatory course. They hypothesized that the meetings could have made students more aware of differences and thus more apprehensive about communicating with foreign students. Because Gullekson et al. (2011) did not survey students prior to the preparatory course, the effects of the preparatory course were unclear. ${ }^{5}$

\footnotetext{
${ }^{5}$ Gullekson, Tucker, Coombs, et al. (2011) highlights the need to control for this effect in subsequent work. Anderson et al. (2006) also implements a longitudinal study to analyze the development of cross-cultural sensitivity through STSA. They utilize a 50 question survey from the Intercultural Development Inventory. Using factor analysis of the individual items, five factors are created which test various aspects of cross-cultural
} 


\section{The Study}

The sample used in this study is drawn from undergraduate students at Elon University who enrolled in a STSA program in the fall semester 2011 and winter term 2012. A total of 23 separate STSA experiences were surveyed. All STSA courses spent between 21-27 days abroad and were noncourse embedded abroad experiences. A total of 607 students were enrolled in Fall 2011 and 589 students participated in Winter 2012, 18 students dropped out between the Fall Term and Winter Term. ${ }^{6}$

Many STSA experiences include some preparatory component either formal or informal (Gullekson et al. 2011). By surveying students prior to the preparatory course, we measure the level of global awareness students have before beginning the STSA sequence. At Elon University, all students enrolled in the STSA experience are required to take a formal preparatory course in the fall immediately preceding the STSA course, taught by the same faculty members who will be leading the STSA program. The objective of the preparatory course is to "begin the learning process and prepare the students in matters of culture and course content in such a way that the students are better able to benefit from the program abroad" (Elon University, 2009). As a result, the preparatory course focuses on content to which students will be exposed while abroad. Controlling both for instructor and for academic content allows us to focus on the effect of learning environment, either at the home institution or abroad, on student outcomes.

The timing of the surveys is as follows. We measure levels of global awareness as each student progresses through the sequence at the disparate times: prior to the preparatory, post- preparatory /pre-STSA, and post-STSA. Figure 1 describes the timing of the data collection.

Figure 1. Timing of the Data Collection

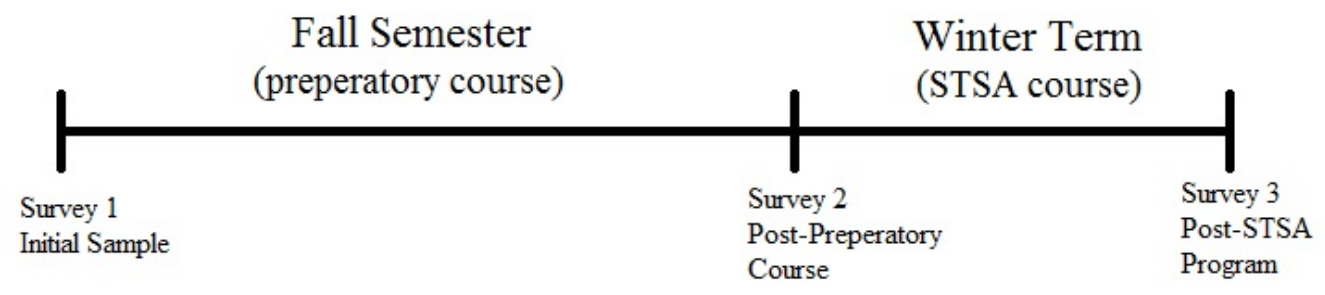

The longitudinal design avoids a potential problem that Chieffo and Griffiths (2004) may experience through the control group; to provide a meaningful comparison between students who

sensitivity. Overall, their results indicate increases in levels of cross-cultural sensitivity. While a preparatory course does not seem to be influencing results, the authors indicate that pause must be given when interpreting their results due to a small sample because cohort sample size was 16 on one STSA with the same instructor

${ }^{6}$ We hypothesize the main reasons are financial (the full cost of the course less a $\$ 500$ deposit was due on October 15, 2011) and medical. 
study abroad and those who remain on campus, the characteristics of these two groups should be similar. If the two groups are not similar, then differences in global awareness between the two groups may be due to differences in the other characteristics rather than participation in the STSA program. For example, STSA programs are more expensive than courses at the home institution. Therefore, the family income of those studying abroad is likely to be higher than the average student. The current study circumvents this problem by following the same student across the three surveys. As a result, we can accurately determine the effect of the STSA program for each student. We also include additional questions to the original survey. These questions ask students to selfreport socioeconomic status and previous experience traveling abroad, both in academic settings and in non-academic settings. This allows us to measure the impact of the most recent STSA experience on those who have already participated in an STSA program prior to the survey and examine the effects on global awareness. ${ }^{7}$ We also have information regarding the specific STSA program in which each student enrolled. The sample has over 23 STSA programs with variations in language exposure, in content and in the underlying model of the program which include university-based abroad programs, service-learning programs, and study tours.

\section{IV: Data Description}

\section{Background Variables}

In addition to the awareness measures, which are described in the following section, the sample reports several demographic controls that may influence global awareness. The sample reports gender, the individual's academic year, the program in which the respondent is enrolled, categories of estimated college GPA, categories of an individual's estimated annual family income, the number of study abroad programs in which the respondent has participated previously, both for a winter term and for a semester and the number of times the respondent has traveled abroad. Table 1 reports the tabulation of these variables for each round. (Tables are located after the text of this article)

The tabulations presented in Table 1 provide a picture of which students choose to study abroad. First, a large percentage of these students are female; more than three quarters of the sample are women. Second, nearly two thirds of the participants come from families in the top two income categories. Third, these students have high academic achievement, measured by their college GPA; more than $90 \%$ of the sample has a GPA of 3.00 or higher. Fourth, students enrolled in these programs are usually in their second, third or fourth year of school. Fifth, the majority of students are in the arts and science program. Finally, most students in the sample have relatively limited experience with study-abroad programs; nearly two thirds of the participants have never completed a study-abroad course.

\section{Awareness Measures}

Following Chieffo and Griffiths (2004), we ask students a number of questions to determine the level of global awareness gained by the study abroad programs. Questions one through nine ask

\footnotetext{
${ }^{7}$ Due to the longitudinal design we eschew a control group.
} 
students to rate the statements using a standard Likert scale (strongly disagree, disagree, neither agree nor disagree, agree, and strongly agree) and questions ten through eighteen ask students to report the frequency with which they do the activity listed. The frequencies are: never, rarely (less than once a week), occasionally (about once a week), frequently (a few times a week) and a lot (more than 10 per week). Table 2 reports the pooled means and standard deviations for each item.

In addition to analyzing how the responses to the questions in Table 2 change after a study abroad program, we perform exploratory factor analysis (EFA) to reduce the number of items into five uncorrelated factors. EFA is a variable reduction technique used to reduce several correlated variables into a smaller number of uncorrelated factors. For example, it is likely that people who frequently think about the "similarities between myself and people from other countries" also frequently think about the differences. ${ }^{8}$ As a result, EFA combines these items into a single variable that can be used in subsequent analyses. The EFA procedure is largely based on the methods described in Costello and Osborne (2005).

The factor analysis results in the construction of five easily interpretable, uncorrelated factors. Table 3 reports each factor and the survey items that describe a large portion of each factor's variation. These values are known as factor loadings; a high factor loading indicates that the item of interest comprises an important component of that factor. A factor loading of 0.3 or higher in absolute value is considered to be noteworthy (Costello and Osborne 2005) and Table 3 reports only loadings of 0.3 or higher. Based on the factor loadings, the researcher can label the factors based on which items explain a large portion of the factor's variation. We label the factors as follows: general awareness, functional knowledge, foreign media exposure, culture and communication, foreign language exposure.

\section{Estimation Strategy and Results}

\section{Estimation Strategy}

To determine the effects of short-term study abroad programs on global awareness, we consider both the complete pooled cross-section and the sample that is restricted to individuals who completed multiple surveys. The pooled cross-section consists of 384 observations, with 103 observations in the first round, 153 observations in the second round and 128 observations in the third round. The restricted sample is somewhat smaller; there are 30 students who completed all three surveys. For the restricted sample, we conduct t-tests on the mean differences between periods assuming unequal variances.

For the pooled cross section, we conduct two separate tests. First, for each survey item and for the factors, we conduct t-tests of the means between survey rounds, assuming unequal variances. This will allow us to determine whether there is a significant difference in awareness between having no class, having a one-hour semester long class, and having a short term study abroad experience.

\footnotetext{
${ }^{8}$ The correlation between these two items is 0.715 . In addition, the correlations between the other items, available upon request, show positive correlations between all of the items, and nearly all of these correlations are significant at the $1 \%$ level
} 
Second, we estimate linear regressions of the survey rounds and the background variables described in the previous section on each of the five factors. The estimated Ordinary Least Squares (OLS) regression is:

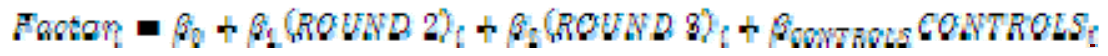

The value $\beta_{0}$ represents the level of the factor in the initial survey prior to the preparatory course, $\beta_{1}$ represents the effect of taking the preparatory one hour course on awareness, and $\beta_{2}$ represents the effect of the short-term study abroad program on awareness. The control variables include program of study, college GPA, family income, number of times a student has travelled abroad, prior experience with study abroad programs, whether the study abroad course is taught in a foreign language and gender.

\section{Results from the Pooled Cross Section}

Tables 4 and 5 report the means for the pooled sample for each factor and each survey item by round. In addition, they report the difference in means and the associated t-statistic testing whether the difference in means equals zero, assuming unequal variance across rounds.

The results in Tables 4 and 5 indicate the following. First, there is no significant change in awareness between the initial sample and sample after the one-hour semester-long course. Between rounds one and two the only item which has a significant increase in its mean is the item "I can explain some aspect of US foreign policy to someone of another country." One possible explanation for these insignificant effects is that the objective of the hour-long semester course is to prepare students for their study abroad programs instead of developing international awareness. Alternatively, it may be difficult to develop international awareness in this type of course. Direct exposure to foreign culture or additional class time may be necessary.

Second, several items and factors show significant increases in mean values between the second and third survey. For the factors, there is a significant increase in general awareness, functional knowledge and foreign media exposure. In addition, between the second and third survey there is a significant increase in the means of several of the items. These items include: knowing how to make a phone call to someone in a different country, interest in attaining fluency in another language, knowledge of the conversion rates between US and a foreign currency, patience with individuals who do not speak English well, reading an article about how Americans are viewed in other countries, watching a non-American television broadcast, looking up something on a map of another country, listening to music sung in a non-English language and thinking about both similarities and differences between the individual and people from another country.

Finally, between rounds one and three, nearly all of the aforementioned items show significant increases in means. In addition, between rounds one and three, there is a significant increase in the means of the communication and culture factor, explaining US foreign policy, developing a greater appreciation for the arts, and thinking about a current issue that is important to people of a developing country. These results suggest that there are significant benefits to global awareness from a short-term study abroad course that do not necessarily exist in a one-hour semester-long course.

Further evidence of the gain in global awareness is reported in Table 6. Table 6 reports the results of the OLS regressions using each of the awareness factors as dependent variables. The main 
coefficients of interest are the ones listed for rounds two and three. The results presented here are consistent with the aforementioned t-tests. First, there is no significant effect of round two on any of the global awareness factors. Second, for the first three factors, there is a significant, positive effect of the study abroad programs; participation in these programs is associated with an increase in the factor variables ranging from 0.21 to 0.35 standard deviations. Interestingly, the controls listed in Table 6 explain a relatively large portion of the variation in functional knowledge, and a relatively small portion of the variation in the other factors. For example, for functional knowledge, prior travel abroad has a large, positive effect. Relative to someone who has never been abroad, someone who has traveled abroad three to five times before has, on average, a factor score that is 0.76 standard deviations higher.

Most of the controls in Table 6 are insignificant. With a few exceptions, program of study does not have an effect on global awareness; relative to an individual in the arts and science program, only the following effects are significant. First, a business student, on average, is associated with a higher level of functional knowledge. Second, individuals both in the education program and in the business program are associated with lower foreign language exposure. Additionally, college GPA has significant effects only for individuals in the lowest GPA category. Relative to individuals in the top GPA category, individuals in the lowest category have significantly higher values of foreign media exposure and foreign language exposure. Further, whether the study abroad course is conducted in another language has a significant positive effect only on the "foreign language exposure." Although this is an unsurprising result, it lends support to the assigned factor label. Finally, male students are more likely to have a value both of functional knowledge and of foreign media exposure.

Tables 7 and 8 report the means and mean differences, respectively, for the factors and for the survey items for individuals who completed the survey in all three rounds. It should be noted from the outset that restricting the sample to individuals who completed all three surveys reduces the sample considerably. For this analysis, there are 90 observations with 30 observations for each round. ${ }^{9}$

The results for the restricted sample are similar to that of the complete sample. Between rounds 1 and 2, a vast majority of the differences are insignificant. There are two items for which individuals report a decrease between the first and second sample. Individuals reported in the second sample that they had a significant decrease in the amount of time they both thought about differences between themselves and people from other countries and looked up something on a map of another country. In addition, the results are similar between the first and third survey and between the second and third survey. In both cases, individuals significantly increased their functional knowledge, increased their knowledge about making phone calls to someone in a different country, increased their ability to explain some aspect of U.S. foreign policy to a person from another country, and increased their knowledge of currency conversion rates.

\footnotetext{
${ }^{9}$ Because only a small subset of students completed all three surveys, we do not estimate regressions for this restricted sample. Instead, we rely on a comparison of means.
} 


\section{VI: Discussion and Conclusion}

The present study examines the effect of short-term study abroad (STSA) programs on global awareness for students enrolled in a program in Fall 2011 and Winter 2012. Using longitudinal data, we examine the effect both of a semester-long preparatory course and of an STSA course on several variables designed to measure various aspects of global awareness. Self-reported survey data allow us to control both for socioeconomic status and for previous experiences abroad. An exploratory factor analysis is used to reduce the numerous awareness measures down to five factors.

The results are consistent with existing findings. For example, Chieffo and Griffiths (2004) report significant, positive effects of STSA coursework on several measures of awareness. Our results indicate a similar finding, both when comparing the means in initial sample to those in the postSTSA sample and when comparing the post- preparatory means to those in the post-STSA sample. Further, when applying a first-difference approach as in Gullekson et al (2011), we find that students experience a significant increase in global awareness, specifically regarding functional knowledge.

Our results extend the existing literature in several important ways. To our knowledge, we are the first study to explicitly account both for socioeconomic status and for past experiences abroad using multivariate regressions. The results suggest that past experiences abroad are important predictors of global awareness, especially functional knowledge. However, even after accounting for these factors, there is still a significant, positive effect of STSA participation on three of the five global awareness factors. Further, the results suggest that the largest gains are in functional knowledge. While this is unsurprising, it is an important result. The STSA programs require students to navigate in a different country and provide hands-on experience in this area, which may be difficult to provide in a traditional course.

Our findings suggest that the preparatory course has no significant direct effect on global awareness across nearly all of the survey items and for all of the factors; this result is robust to specification and using the pooled cross section or the matched sample. Further, comparing the differences in means between the first and third surveys and between second and third surveys indicate no appreciable difference in the results. Thus, we find no evidence of an apprehension effect a result of the preparatory course, suggested as a possibility by Gullekson et al (2011). Our results suggest that increases in the levels of global awareness are difficult to achieve at the home institution, even when exposing students to similar academic content and instructional faculty. However, we cannot rule out the possibility that the preparatory course may have an indirect effect on the development of global awareness. It may be the case that while students do not experience statistically significant gains in global awareness prior to going abroad, the preparatory course may prepare students to maximize the potential gains from the STSA experience. Such courses prepare students for their experience abroad, likely allowing them to acclimate to their new environment and academic content more quickly and easily. Our results open the door to future work determining the effects of preparatory course on STSA experiences, as well as retention rates of global awareness gained through STSA sequences. 


\section{References}

Anderson, Philip H., Leigh Lawton, Richard Rexeisen, and Ann C. Hubbard. 2006. "Short-term Study Abroad and Intercultural Sensitivity: A Pilot Study." International Journal of Intercultural Relations 30: 457-469.

Association of American Colleges, Universities, and National Leadership Council (US). 2007. College Learning for the New Global Century: A Report from the National Leadership Council for Liberal Education \& America's Promise.

Carlson, Jerry S., Barbara B. Burn, and David Yachimowicz. 1990. Study Abroad: The Experience of American Undergraduates. Praeger.

Carlson, Jerry S., and Keith F. Widaman. 1988. "The Effects of Study Abroad During College on Attitudes Toward Other Cultures." International Journal of Intercultural Relations 12 (1) (January): 1-17. doi:10.1016/0147-1767(88)90003-X.

Chieffo, Lisa, and Lesa Griffiths. 2004. "Large-Scale Assessment of Student Attitudes After a ShortTerm Study Abroad Program." The Interdisciplinary Journal of Study Abroad 10 (4): 165-177.

Chow, Patricia, and Ashley Villarreal. 2011. Open Doors: Report on International Educational Exchange. Institute of International Education. http://www.iie.org/en/Research-andPublications/Publications-and-Reports/IIE-Bookstore/Open-Doors-2011.

Costello, Anna B., and Jason W. Osborne. 2005. "Best Practices in Exploratory Factor Analysis: Four Recommendations for Getting the Most from Your Analysis.” Practical Assessment, Research \& Evaluation 10: 173-178.

DeLoach,, Stephen, Leila Saliba, Victoria Smith, and Thomas Tiemann. 2003. "Developing a Global Mindset Through Short-Term Study Abroad: A Group Discussion Approach.” Journal of Teaching in International Business 15: 37-59.

Dwyer, Mary M. 2004. "More Is Better: The Impact of Study Abroad Program Duration.” Frontiers: The Interdisciplinary Journal of Study Abroad 10 (Fall): 151-163.

Elon University, 2009. "New Course Proposal for One-Credit Hour Preparatory Course Associated with Short-Term Study Abroad." Internal Report. Elon, NC: Basirico, Laurence.

Fischer, Karin. 2009. "Short Study-Abroad Trips Can Have Lasting Effect, Research Suggests." The Chronicle of Higher Education, January 20. http://chronicle.com/daily/2009/02/12191n.htm.

Gullekson, Nicole L., Mary L. Tucker, Garth Coombs, and Scott B. Wright. 2011. "Examining Intercultural Growth for Business Students in Short-Term Study Abroad Programs: Too Good to Be True?" Journal of Teaching in International Business 22 (2) (April): 91-106. doi:10.1080/08975930.2011.615672.

Ingraham, Edward C., and Debra L. Peterson. 2004. "Assessing the Impact of Study Abroad on Student Learning at Michigan State University." Frontiers: The Interdisciplinary Journal of Study Abroad 10 (Fall): 83-100. 
Jon, Jae-Eun, and Gerald W. Fry. 2009. "The Long-term Impact of Undergraduate Study Abroad Experience: Implications for Higher Education" presented at the Association for the Study of Higher Education Annual Conference., Vancouver, B.C., Canada.

Langran, Irene V., Elizabeth Langran, and Kathy Ozment. 2009. "Transforming Today's Students into Tomorrow's Global Citizens: Challenges for U.S. Educators.” New Global Studies 3 (1) ( 13). doi:10.2202/1940-0004.1056. http://www.degruyter.com/view/j/ngs.2009.3.1/ngs.2009.3.1.1056/ngs.2009.3.1.1056.xml.

Lewis, Tammy L., and Richard A. Niesenbaum. 2005a. "Extending the Stay: Using CommunityBased Research and Service Learning to Enhance Short-Term Study Abroad." Journal of Studies in International Education 9: 251-264.

— 2005b. "The Benefits of Short-Term Study Abroad." The Chronicle of Higher Education (June 3).

Ogden, Anthony C. 2010. "Education Abroad and the Making of Global Citizens: Assessing Learning Outcomes of Course-embedded, Faculty-led International Programming”. Ph.D. diss., The Pennsylvania State University, 2010. URL: https://etda.libraries.psu.edu/paper/10524/6225.

Paige, R. Michael, Gerald W. Fry, Elizabeth M. Stallman, Jasmina Josić, and Jae-Eun Jon. 2009. "Study Abroad for Global Engagement: The Long-term Impact of Mobility Experiences." Intercultural Education 20 (sup1) (January): S29-S44. doi:10.1080/14675980903370847. Sachai, Daniel, Neil Brasher, and Scott Fee. 2009. "Three Models for Short-Term Study Abroad." Journal of Management Education 34 (5): 645-670. 


\section{Tables}

Table 1: Descriptive Statistics

\begin{tabular}{|c|c|c|c|c|c|}
\hline Variable & Category & All Rounds & Round 1 & Round 2 & Round 3 \\
\hline \multirow[t]{2}{*}{ Gender } & Female & 76.73 & 83.49 & 74.53 & 73.88 \\
\hline & Male & 23.27 & 16.51 & 25.47 & 26.12 \\
\hline \multirow[t]{5}{*}{ Family Income } & Less than $\$ 50,000$ & 3.52 & 5.41 & 3.21 & 2.29 \\
\hline & $\$ 50,000-\$ 74,999$ & 12.56 & 9.91 & 12.18 & 15.27 \\
\hline & $\begin{array}{l}\$ 75,000-\$ 99,000 \\
\$ 100,000-\end{array}$ & 16.83 & 14.41 & 17.95 & 17.56 \\
\hline & $\$ 149,000$ & 28.14 & 27.93 & 28.21 & 28.24 \\
\hline & Above $\$ 150,000$ & 38.94 & 42.34 & 39.46 & 36.64 \\
\hline \multirow[t]{4}{*}{ Estimated College GPA } & $2.49-2.00$ & 0.49 & 0.88 & 0.00 & 0.74 \\
\hline & $2.99-2.50$ & 9.47 & 5.26 & 9.88 & 12.50 \\
\hline & $3.49-3.00$ & 41.50 & 35.96 & 43.21 & 44.12 \\
\hline & $4.0-3.5$ & 48.54 & 57.89 & 46.91 & 42.65 \\
\hline \multirow[t]{5}{*}{ Academic Year } & First Year & 2.69 & 2.65 & 1.88 & 3.68 \\
\hline & Second Year & 40.10 & 40.71 & 43.13 & 36.03 \\
\hline & Third Year & 30.32 & 31.86 & 28.75 & 30.88 \\
\hline & Fourth Year & 26.41 & 24.78 & 25.63 & 28.68 \\
\hline & Fifth Year & 0.49 & 0.00 & 0.63 & 0.74 \\
\hline \multirow[t]{5}{*}{ Academic Program } & Arts \& Sciences & 51.46 & 48.25 & 54.94 & 50.00 \\
\hline & Business & 20.15 & 21.93 & 17.28 & 22.06 \\
\hline & Communications & 20.39 & 22.81 & 19.75 & 19.12 \\
\hline & Education & 5.58 & 4.39 & 6.17 & 5.88 \\
\hline & Undecided & 2.43 & 2.63 & 1.85 & 2.94 \\
\hline \multirow[t]{5}{*}{$\begin{array}{l}\text { Travelled Abroad (\# of } \\
\text { times) }\end{array}$} & Not At All & 12.93 & 18.75 & 18.52 & 1.47 \\
\hline & 1-2 Times & 33.17 & 30.36 & 30.86 & 38.24 \\
\hline & 3-5 Times & 28.29 & 25.89 & 27.16 & 31.62 \\
\hline & $6-8$ Times & 8.54 & 7.14 & 9.88 & 8.09 \\
\hline & More than 8 times & 17.07 & 17.86 & 13.58 & 20.59 \\
\hline \multirow{6}{*}{$\begin{array}{l}\text { Studied Abroad (\# of } \\
\text { times) }\end{array}$} & & & & & \\
\hline & $\begin{array}{l}0 \text { Times } \\
1 \text { Time }\end{array}$ & $\begin{array}{l}63.26 \\
28.74\end{array}$ & 64.04 & $\begin{array}{l}62.43 \\
31.06\end{array}$ & $\begin{array}{l}63.24 \\
30.88\end{array}$ \\
\hline & 2 Times & $\begin{array}{l}20.14 \\
5.60\end{array}$ & 8.77 & 4.35 & 4.41 \\
\hline & 3 Times & 1.46 & 2.63 & 0.62 & 1.47 \\
\hline & 4 Times or more & 0.97 & 1.75 & 1.24 & 0.00 \\
\hline & $N$ & 384 & 103 & 153 & 128 \\
\hline
\end{tabular}


Table 2: Survey Questions-Pooled Statistics

\begin{tabular}{|c|c|c|c|c|}
\hline Survey Item & Mean & Std. Dev. & Min & Max \\
\hline $\begin{array}{l}\text { I know how to make a phone call to someone in a different } \\
\text { country. }\end{array}$ & 3.340 & 1.304 & 1 & 5 \\
\hline $\begin{array}{l}\text { I understand how foreign manufacturing affects the price of } \\
\text { consumer goods in the United States. }\end{array}$ & 3.677 & 1.042 & 1 & 5 \\
\hline $\begin{array}{l}\text { Over the past month, I have become more interested in } \\
\text { attaining fluency in another language. }\end{array}$ & 3.704 & 1.127 & 1 & 5 \\
\hline $\begin{array}{l}\text { I can explain some aspect of U.S. foreign policy to someone } \\
\text { from another country. }\end{array}$ & 3.398 & 1.088 & 1 & 5 \\
\hline $\begin{array}{l}\text { I know the currency conversion rate for the U.S. dollar to at } \\
\text { least one other foreign country. }\end{array}$ & 4.073 & 1.101 & 1 & 5 \\
\hline $\begin{array}{l}\text { I am patient with people in the U.S. who don't speak English } \\
\text { well. }\end{array}$ & 4.104 & 0.858 & 1 & 5 \\
\hline $\begin{array}{l}\text { I am comfortable in my ability to communicate with } \\
\text { members of at least one foreign culture in their native } \\
\text { language. }\end{array}$ & 3.228 & 1.233 & 1 & 5 \\
\hline I am interested in learning more about world geography. & 4.002 & 0.908 & 1 & 5 \\
\hline $\begin{array}{l}\text { Over the past month, I have developed a greater } \\
\text { appreciation for the arts (in the form of buildings, paintings, } \\
\text { literary works, etc.). }\end{array}$ & 3.818 & 0.948 & 1 & 5 \\
\hline $\begin{array}{l}\text { I read an article, watched a TV show, or spoke to someone } \\
\text { about how Americans are viewed by people from other } \\
\text { countries. }\end{array}$ & 2.786 & 0.870 & 1 & 5 \\
\hline $\begin{array}{l}\text { I watched a non-American TV station, news broadcast, or } \\
\text { television show. }\end{array}$ & 2.413 & 1.116 & 1 & 5 \\
\hline $\begin{array}{l}\text { I have consciously withheld judgment on a controversial } \\
\text { international event until I learned more facts. }\end{array}$ & 3.357 & 0.942 & 1 & 5 \\
\hline $\begin{array}{l}\text { I thought about the differences between myself and people } \\
\text { from other countries. }\end{array}$ & 3.704 & 0.907 & 1 & 5 \\
\hline I looked up something on a map of another country. & 3.097 & 0.967 & 1 & 5 \\
\hline $\begin{array}{l}\text { I thought about the similarities between myself and people } \\
\text { from other countries. }\end{array}$ & 3.483 & 0.908 & 1 & 5 \\
\hline I looked up a non-English word in a dictionary. & 2.932 & 1.159 & 1 & 5 \\
\hline $\begin{array}{l}\text { I thought about a current issue that's important to the } \\
\text { people of a developing country. }\end{array}$ & 3.296 & 0.971 & 1 & 5 \\
\hline $\begin{array}{l}\text { I have listened to music sung in a language other than } \\
\text { English. }\end{array}$ & 3.124 & 1.180 & 1 & 5 \\
\hline
\end{tabular}


Table 3: Awareness Factors and Their Components

\begin{tabular}{|c|c|c|}
\hline Survey Item/Factor Name & Loading & Uniqueness \\
\hline \multicolumn{3}{|l|}{ Factor 1: General Awareness } \\
\hline $\begin{array}{l}\text { I thought about the similarities between myself and people from } \\
\text { other countries. }\end{array}$ & 0.874 & 0.185 \\
\hline $\begin{array}{l}\text { I thought about the differences between myself and people from } \\
\text { other countries. }\end{array}$ & 0.770 & 0.373 \\
\hline I looked up something on a map of another country. & 0.533 & 0.630 \\
\hline $\begin{array}{l}\text { I thought about a current issue that's important to the people of a } \\
\text { developing country. }\end{array}$ & 0.490 & 0.664 \\
\hline $\begin{array}{l}\text { I have consciously withheld judgment on a controversial } \\
\text { international event until I learned more facts. }\end{array}$ & 0.484 & 0.717 \\
\hline $\begin{array}{l}\text { I read an article, watched a TV show, or spoke to someone about } \\
\text { how Americans are viewed by people from other countries. }\end{array}$ & 0.438 & 0.575 \\
\hline \multicolumn{3}{|l|}{ Factor 2: Functional Knowledge } \\
\hline $\begin{array}{l}\text { I know how to make a phone call to someone in a different } \\
\text { country. }\end{array}$ & 0.666 & 0.515 \\
\hline $\begin{array}{l}\text { I know the currency conversion rate for the U.S. dollar to at least } \\
\text { one other foreign currency. }\end{array}$ & 0.579 & 0.574 \\
\hline $\begin{array}{l}\text { I understand how foreign manufacturing affects the price of } \\
\text { consumer goods in the United States. }\end{array}$ & 0.532 & 0.692 \\
\hline $\begin{array}{l}\text { I can explain some aspect of U.S. foreign policy to someone from } \\
\text { another country. }\end{array}$ & 0.502 & 0.691 \\
\hline \multicolumn{3}{|l|}{ Factor 3: Foreign Media Exposure } \\
\hline $\begin{array}{l}\text { I watched a non-American TV station, news broadcast, or } \\
\text { television show. }\end{array}$ & 0.887 & 0.134 \\
\hline $\begin{array}{l}\text { I read an article, watched a TV show, or spoke to someone about } \\
\text { how Americans are viewed by people from other countries. }\end{array}$ & 0.382 & 0.575 \\
\hline I have listened to music sung in a language other than English. & 0.364 & 0.658 \\
\hline \multicolumn{3}{|l|}{ Factor 4: Communication and Culture } \\
\hline I am patient with people in the U.S. who don't speak English well. & 0.564 & 0.599 \\
\hline I am interested in learning more about world geography. & 0.531 & 0.658 \\
\hline $\begin{array}{l}\text { Over the semester, I have developed a greater appreciation for } \\
\text { the arts (in the form of buildings, paintings, literary works etc...). }\end{array}$ & 0.506 & 0.666 \\
\hline $\begin{array}{l}\text { Over the semester, I have become more interested in attaining } \\
\text { fluency in another language. }\end{array}$ & 0.450 & 0.632 \\
\hline $\begin{array}{l}\text { I am comfortable in my ability to communicate with members of } \\
\text { at least one foreign culture in their native language. }\end{array}$ & 0.332 & 0.708 \\
\hline \multicolumn{3}{|l|}{ Factor 5: Foreign Language Exposure } \\
\hline I looked up a non-English word in a dictionary. & 0.662 & 0.463 \\
\hline \multirow{2}{*}{$\begin{array}{l}\text { I have listened to music sung in a language other than English. } \\
\text { I am comfortable in my ability to communicate with members of } \\
\text { at least one foreign culture in their native language. }\end{array}$} & 0.401 & 0.658 \\
\hline & 0.336 & 0.708 \\
\hline
\end{tabular}


Mark R. Kurt, Neal H. Olitsky, Paul Geis

Table 4: T-Tests of Means in the Pooled Cross-Section, Factors

\begin{tabular}{|c|c|c|c|c|c|c|c|c|c|}
\hline & & & & \multicolumn{6}{|c|}{ "Testing Differences in Means } \\
\hline & \multicolumn{3}{|c|}{ Means by Round } & \multicolumn{2}{|c|}{$(2)-(1)$} & \multicolumn{2}{|c|}{$(3)-(2)$} & \multicolumn{2}{|c|}{$(3)-(1)$} \\
\hline & 1 & 2 & 3 & Diff. & T-stat & Diff. & T-Stat & Diff. & T-Stat \\
\hline Factor 1 General Awareness & -0.12 & -0.08 & 0.19 & 0.04 & 0.34 & 0.27 & $2.53^{*}$ & 0.31 & $2.71^{\star \star}$ \\
\hline Factor 2: Functional Knowledge & -0.15 & -0.1 & 0.24 & 0.05 & 0.49 & 0.34 & $3.77^{\star \star *}$ & 0.39 & $3.83^{\star \star *}$ \\
\hline Factor 3: Foreign Media Exposure & -0.16 & -0.09 & 0.24 & 0.07 & 0.63 & 0.33 & $3.13^{\star \star}$ & 0.4 & $3.53^{\star \star *}$ \\
\hline Factor 4: Communication and Culture & -0.1 & -0.02 & 0.11 & 0.08 & 0.93 & 0.13 & 1.35 & 0.21 & $2.06^{\star}$ \\
\hline Factor 5: Foreign Language Exposure & 0.04 & -0.05 & 0.02 & -0.09 & -1.01 & 0.07 & 0.79 & -0.02 & 0.02 \\
\hline
\end{tabular}


Table 5: T-Tests of Means in the Pooled Cross-Section, Survey Questions

\begin{tabular}{|c|c|c|c|c|c|c|c|c|c|}
\hline & & & & \multicolumn{6}{|c|}{ 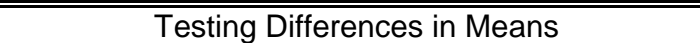 } \\
\hline & \multicolumn{3}{|c|}{ Means by Round } & \multicolumn{2}{|c|}{ (2) - (1) } & \multicolumn{2}{|c|}{ (3) - (2) } & \multicolumn{2}{|c|}{ (3) - (1) } \\
\hline & 1 & 2 & 3 & Diff. & T-stat & Diff. & T-Stat & Diff. & T-Stat \\
\hline $\begin{array}{l}\text { I know how to make a phone call to } \\
\text { someone in a different country. }\end{array}$ & 3.11 & 3.1 & 3.9 & -0.01 & $\begin{array}{l}-0.08 \\
\end{array}$ & 0.8 & $6.02^{\star \star \star}$ & 0.79 & $5.08^{\star \star \star}$ \\
\hline $\begin{array}{l}\text { I understand how foreign } \\
\text { manufacturing affects the price of } \\
\text { consumer goods in the US. }\end{array}$ & 3.69 & 3.71 & 3.64 & 0.02 & 0.15 & -0.07 & -0.56 & -0.05 & 0.05 \\
\hline $\begin{array}{l}\text { Over the semester, I have become } \\
\text { more interested in attaining fluency in } \\
\text { another language. }\end{array}$ & 3.47 & 3.55 & 3.94 & 0.08 & 0.6 & 0.39 & $3.16^{\star \star}$ & 0.47 & $3.31^{\star \star}$ \\
\hline $\begin{array}{l}\text { I can explain some aspect of U.S. } \\
\text { foreign policy to someone from another } \\
\text { country. }\end{array}$ & 3.16 & 3.44 & 3.55 & 0.28 & $2.19^{\star}$ & 0.11 & 0.9 & 0.39 & $2.81^{\star *}$ \\
\hline $\begin{array}{l}\text { I know the currency conversion rate for } \\
\text { the U.S. dollar to at least one other } \\
\text { foreign currency. }\end{array}$ & 3.78 & 3.82 & 4.62 & 0.04 & 0.27 & 0.8 & $7.78^{\star \star \star}$ & 0.84 & $6.70^{\star \star \star}$ \\
\hline $\begin{array}{l}\text { I am patient with people in the U.S. } \\
\text { who don't speak English well. }\end{array}$ & 4.06 & 4 & 4.23 & -0.06 & -0.55 & 0.23 & $2.38^{\star}$ & 0.17 & -0.17 \\
\hline $\begin{array}{l}\text { I am comfortable in my ability to } \\
\text { communicate with members of at least } \\
\text { one foreign culture in their native } \\
\text { language. }\end{array}$ & 3.18 & 3.25 & 3.28 & 0.07 & 0.48 & 0.03 & 0.2 & 0.1 & -0.1 \\
\hline $\begin{array}{l}\text { I am interested in learning more about } \\
\text { world geography. }\end{array}$ & 4.02 & 3.92 & 4.03 & -0.1 & -0.98 & 0.11 & 1.12 & 0.01 & -0.01 \\
\hline $\begin{array}{l}\text { Over the past month, I have developed } \\
\text { a greater appreciation for the arts (in } \\
\text { the form of buildings, paintings, literary } \\
\text { works, etc.). }\end{array}$ & 3.57 & 3.77 & 3.97 & 0.2 & 1.79 & 0.2 & 1.93 & 0.4 & 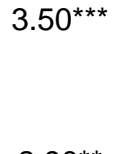 \\
\hline $\begin{array}{l}\text { I read an article, watched a TV show, } \\
\text { or spoke to someone about how } \\
\text { Americans are viewed by people from } \\
\text { other countries. }\end{array}$ & 2.63 & 2.73 & 2.93 & 0.1 & 1.08 & 0.2 & $2.05^{*}$ & 0.3 & $2.90^{\star *}$ \\
\hline $\begin{array}{l}\text { I watched a non-American TV station, } \\
\text { news broadcast, or television show. }\end{array}$ & 2.19 & 2.24 & 2.82 & 0.05 & 0.41 & 0.58 & $4.78^{\star \star \star}$ & 0.63 & $4.87^{\star \star \star}$ \\
\hline $\begin{array}{l}\text { I have consciously withheld judgment } \\
\text { on a controversial international event } \\
\text { until I learned more facts. }\end{array}$ & 3.3 & 3.32 & 3.4 & 0.02 & 0.19 & 0.08 & 0.81 & 0.1 & -0.1 \\
\hline $\begin{array}{l}\text { I thought about the differences } \\
\text { between myself and people from other } \\
\text { countries. }\end{array}$ & 3.55 & 3.61 & 3.87 & 0.06 & 0.5 & 0.26 & $2.52^{*}$ & 0.32 & $2.80^{\star *}$ \\
\hline $\begin{array}{l}\text { I looked up something on a map of } \\
\text { another country. }\end{array}$ & 2.96 & 2.98 & 3.32 & 0.02 & 0.16 & 0.34 & $3.19^{\star *}$ & 0.36 & $3.01^{* *}$ \\
\hline $\begin{array}{l}\text { I thought about the similarities between } \\
\text { myself and people from other } \\
\text { countries. }\end{array}$ & 3.33 & 3.36 & 3.68 & 0.03 & 0.33 & 0.32 & $3.02^{\star *}$ & 0.35 & $3.24^{\star *}$ \\
\hline $\begin{array}{l}\text { I looked up a non-English word in a } \\
\text { dictionary. }\end{array}$ & 2.96 & 2.83 & 2.98 & -0.13 & -0.96 & 0.15 & 1.16 & 0.02 & -0.02 \\
\hline $\begin{array}{l}\text { I thought about a current issue that's } \\
\text { important to the people of a developing } \\
\text { country. }\end{array}$ & 3.14 & 3.28 & 3.41 & 0.14 & 1.27 & 0.13 & 1.21 & 0.27 & $2.28^{\star}$ \\
\hline $\begin{array}{l}\text { I have listened to music sung in a } \\
\text { language other than English. }\end{array}$ & 3.06 & 3 & 3.34 & -0.06 & -0.43 & 0.34 & $2.54^{*}$ & 0.28 & $2.10^{*}$ \\
\hline
\end{tabular}

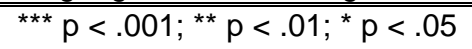


Mark R. Kurt, Neal H. Olitsky, Paul Geis

Table 6: OLS Regression Results

\begin{tabular}{|c|c|c|c|c|c|c|}
\hline & & Factor 1 & Factor 2 & Factor 3 & Factor 4 & Factor 5 \\
\hline \multirow[t]{4}{*}{ Survey Round } & \multirow[t]{2}{*}{ Round 2} & 0.039 & 0.042 & 0.084 & 0.038 & -0.085 \\
\hline & & $(0.116)$ & $(0.097)$ & $(0.115)$ & $(0.096)$ & $(0.096)$ \\
\hline & \multirow[t]{2}{*}{ Round 3} & $0.307^{*}$ & $0.212^{\star}$ & $0.344^{\star \star}$ & 0.12 & -0.033 \\
\hline & & $(0.128)$ & $(0.105)$ & $(0.121)$ & (0.109) & $(0.107)$ \\
\hline \multirow[t]{8}{*}{ Program of Study } & \multirow[t]{2}{*}{ Undeclared } & -0.351 & -0.406 & -0.415 & -0.098 & 0.239 \\
\hline & & $(0.446)$ & $(0.251)$ & $(0.230)$ & $(0.289)$ & $(0.214)$ \\
\hline & \multirow[t]{2}{*}{ Education } & 0.105 & 0.069 & -0.154 & 0.125 & $-0.340^{*}$ \\
\hline & & $(0.191)$ & $(0.151)$ & $(0.196)$ & $(0.132)$ & $(0.159)$ \\
\hline & \multirow[t]{2}{*}{ Communications } & -0.079 & -0.083 & 0.075 & 0.005 & 0.032 \\
\hline & & $(0.129)$ & $(0.091)$ & $(0.112)$ & $(0.098)$ & $(0.107)$ \\
\hline & \multirow[t]{2}{*}{ Business } & -0.197 & $0.244^{*}$ & -0.15 & 0.016 & -0.183 \\
\hline & & $(0.124)$ & $(0.097)$ & $(0.114)$ & $(0.096)$ & $(0.094)$ \\
\hline \multirow{6}{*}{ Est. College GPA } & \multirow[t]{2}{*}{$2.49-2.00$} & 0.211 & 0.362 & $0.531^{* \star}$ & 0.025 & $0.375^{\star}$ \\
\hline & & $(0.311)$ & $(0.196)$ & $(0.204)$ & $(0.588)$ & $(0.164)$ \\
\hline & \multirow[t]{2}{*}{$2.99-2.50$} & -0.183 & 0.129 & 0.049 & 0.089 & -0.204 \\
\hline & & $(0.172)$ & $(0.134)$ & $(0.173)$ & $(0.169)$ & $(0.136)$ \\
\hline & \multirow[t]{2}{*}{$3.49-3.00$} & 0.027 & -0.026 & 0.041 & 0.091 & 0.073 \\
\hline & & $(0.102)$ & $(0.084)$ & $(0.101)$ & $(0.085)$ & $(0.088)$ \\
\hline \multirow[t]{8}{*}{ Est. Family Income } & \multirow[t]{2}{*}{$\$ 50,000-\$ 74,999$} & -0.265 & -0.047 & -0.479 & -0.08 & 0.22 \\
\hline & & $(0.303)$ & $(0.183)$ & $(0.309)$ & $(0.170)$ & $(0.190)$ \\
\hline & \multirow[t]{2}{*}{$\$ 75,000-\$ 99,999$} & -0.414 & -0.177 & $-0.733^{\star}$ & -0.225 & -0.07 \\
\hline & & $(0.288)$ & $(0.182)$ & $(0.290)$ & $(0.167)$ & $(0.178)$ \\
\hline & \multirow[t]{2}{*}{$\$ 100,000-\$ 149,999$} & -0.261 & -0.09 & -0.397 & -0.258 & 0.004 \\
\hline & & $(0.282)$ & $(0.173)$ & $(0.287)$ & $(0.153)$ & $(0.170)$ \\
\hline & \multirow[t]{2}{*}{ Above $\$ 150,000$} & -0.289 & -0.011 & -0.428 & $-0.588^{\star \star *}$ & 0 \\
\hline & & $(0.282)$ & $(0.175)$ & $(0.287)$ & $(0.165)$ & $(0.164)$ \\
\hline \multirow[t]{8}{*}{ \# Times Traveled Abroad } & \multirow[t]{2}{*}{ 1-2 Times } & 0.201 & $0.478^{\star * \star}$ & 0.054 & 0.125 & -0.001 \\
\hline & & $(0.154)$ & $(0.137)$ & $(0.159)$ & $(0.133)$ & $(0.131)$ \\
\hline & \multirow[t]{2}{*}{ 3-5 Times } & -0.044 & $0.764^{\star \star \star}$ & -0.037 & 0.052 & -0.018 \\
\hline & & $(0.160)$ & $(0.142)$ & $(0.169)$ & $(0.140)$ & $(0.142)$ \\
\hline & \multirow[t]{2}{*}{ 6-8 Times } & 0.215 & $0.684^{\star \star *}$ & -0.19 & 0.256 & -0.001 \\
\hline & & $(0.239)$ & $(0.182)$ & $(0.214)$ & $(0.174)$ & $(0.190)$ \\
\hline & \multirow[t]{2}{*}{ More than 8 Times } & 0.263 & $0.825^{\star * *}$ & -0.071 & 0.117 & -0.055 \\
\hline & & $(0.170)$ & $(0.162)$ & $(0.192)$ & $(0.162)$ & $(0.156)$ \\
\hline Other Controls & \# of previous STSAs & 0.039 & 0.053 & 0.119 & 0.008 & 0.084 \\
\hline & & $(0.069)$ & $(0.055)$ & $(0.080)$ & $(0.060)$ & $(0.066)$ \\
\hline & \# of semester long & -0.101 & $0.441^{\star * \star}$ & 0.097 & 0 & $0.264^{*}$ \\
\hline & & $(0.113)$ & $(0.089)$ & $(0.112)$ & $(0.106)$ & $(0.110)$ \\
\hline & Course in a Foreign Lang. & 0.009 & 0.079 & 0.067 & 0.072 & $0.356 * \star \star$ \\
\hline & & $(0.100)$ & $(0.079)$ & $(0.097)$ & $(0.082)$ & $(0.078)$ \\
\hline & Male & 0.125 & $0.354^{\star \star \star}$ & $0.349 * \star$ & -0.048 & -0.113 \\
\hline & & $(0.126)$ & $(0.090)$ & $(0.117)$ & $(0.091)$ & $(0.094)$ \\
\hline & Constant & 0.072 & $-0.859 * \star \star$ & 0.153 & 0.101 & -0.181 \\
\hline & & $(0.294)$ & $(0.173)$ & $(0.286)$ & $(0.160)$ & $(0.167)$ \\
\hline & Adjusted R-Square & 0.01 & 0.218 & 0.05 & 0.035 & 0.092 \\
\hline & $\begin{array}{l}\text { P-Value }\left(\mathrm{H}_{0} \text { : All Coeffs. }\right. \\
\text { Sig) }\end{array}$ & 0.106 & 0 & 0 & 0.007 & 0 \\
\hline & $N$ & 384 & 384 & 384 & 384 & 384 \\
\hline
\end{tabular}

Robust standard errors are provided below each estimate in parentheses. The reference categories for program of study, college GPA and number of times traveled abroad are, respectively, Arts and Sciences, 3.50 - 4.00, under $\$ 50,000$ and zero times

*** $p<.001 ;{ }^{* *} p<.01 ;{ }^{*} p<0.05$ 
Table 7: T-Tests for Means of the Differences in the Matched Sample, Factors

\begin{tabular}{|c|c|c|c|c|c|c|c|c|c|}
\hline & & & & \multicolumn{6}{|c|}{ Testing the Means of the Differences } \\
\hline & \multicolumn{3}{|c|}{ Means By Round } & \multicolumn{2}{|c|}{$(2)-(1)$} & \multicolumn{2}{|c|}{$(3)-(1)$} & \multicolumn{2}{|c|}{ (3) - (2) } \\
\hline & 1 & 2 & 3 & Diff & T-Stat & Diff & T-Stat & Diff & T-Stat \\
\hline Factor 1: General Awareness & $\begin{array}{c}- \\
0.01\end{array}$ & $\overline{-}$ & 0.17 & $0 . \overline{16}$ & -1.02 & 0.33 & 1.48 & 0.17 & 0.92 \\
\hline Factor 2: Functional Knowledge & $\begin{array}{c}- \\
0.11\end{array}$ & $\begin{array}{c}- \\
0.05\end{array}$ & 0.43 & 0.05 & 0.43 & 0.49 & $4.82^{\star \star \star}$ & 0.54 & $4.04^{\star \star \star}$ \\
\hline Factor 3: Foreign Media Exposure & 0.18 & 0.09 & 0.07 & 0.09 & -0.62 & $\overline{-}$ & -0.10 & 0.11 & -0.59 \\
\hline Factor 4: Communication and Culture & 0.02 & 0.04 & 0.20 & 0.02 & 0.20 & 0.16 & 1.20 & 0.18 & 1.35 \\
\hline Factor 5: Foreign Language Exposure & 0.04 & 0.01 & $\begin{array}{c}- \\
0.21\end{array}$ & $0 . \overline{-}$ & -0.18 & $\begin{array}{c}- \\
0.22\end{array}$ & -1.40 & $\begin{array}{c}- \\
0.24\end{array}$ & -1.64 \\
\hline
\end{tabular}


Mark R. Kurt, Neal H. Olitsky, Paul Geis

Table 8: T-Tests for Means of the Differences in the Matched Sample, Survey Questions

\begin{tabular}{|c|c|c|c|c|c|c|c|c|c|}
\hline & & & & \multicolumn{6}{|c|}{ Testing the Means of the Differences } \\
\hline & \multicolumn{3}{|c|}{ Means By Round } & \multicolumn{2}{|c|}{$(2)-(1)$} & \multicolumn{2}{|c|}{$(3)-(1)$} & \multicolumn{2}{|c|}{ (3) - (2) } \\
\hline & 1 & 2 & 3 & Diff & T-Stat & Diff & T-Stat & Diff & T-Stat \\
\hline $\begin{array}{l}\text { I know how to make a phone call to } \\
\text { someone in a different country. } \\
\text { I understand how foreign }\end{array}$ & 3.33 & 3.23 & 4.03 & $0 . \overline{10}$ & -0.55 & 0.80 & $3.61^{\star \star}$ & 0.70 & $2.97^{* *}$ \\
\hline $\begin{array}{l}\text { manufacturing affects the price of } \\
\text { consumer goods in the US. }\end{array}$ & 3.63 & 3.80 & 3.67 & 0.17 & 0.87 & $0 . \overline{13}$ & -0.89 & 0.03 & 0.21 \\
\hline $\begin{array}{l}\text { Over the semester, I have become } \\
\text { more interested in attaining fluency in } \\
\text { another language. }\end{array}$ & 3.77 & 3.63 & 4.03 & $0 . \overline{13}$ & -0.68 & 0.40 & 1.99 & 0.27 & 1.22 \\
\hline $\begin{array}{l}\text { I can explain some aspect of U.S. } \\
\text { foreign policy to someone from } \\
\text { another country. }\end{array}$ & 3.33 & 3.33 & 3.83 & 0.00 & 0.00 & 0.50 & $3.34^{\star \star}$ & 0.50 & $2.41^{*}$ \\
\hline $\begin{array}{l}\text { I know the currency conversion rate } \\
\text { for the U.S. dollar to at least one other } \\
\text { foreign currency. }\end{array}$ & 3.90 & 3.93 & 4.70 & 0.03 & 0.13 & 0.77 & $4.04^{\star \star \star}$ & 0.80 & 3.31 ** \\
\hline $\begin{array}{l}\text { I am patient with people in the U.S. } \\
\text { who don't speak English well. } \\
\text { I am comfortable in my ability to }\end{array}$ & 4.17 & 4.13 & 4.37 & 0.03 & -0.21 & 0.23 & 1.37 & 0.20 & 1.65 \\
\hline $\begin{array}{l}\text { communicate with members of at least } \\
\text { one foreign culture in their native } \\
\text { language. }\end{array}$ & 3.30 & 3.40 & 3.47 & 0.10 & 0.47 & 0.07 & 0.30 & 0.17 & 0.66 \\
\hline $\begin{array}{l}\text { I am interested in learning more about } \\
\text { world geography. }\end{array}$ & 4.13 & 4.00 & 3.97 & $0 . \overline{13}$ & -0.72 & $\overline{-} 03$ & -0.24 & $0 . \overline{17}$ & -0.90 \\
\hline $\begin{array}{l}\text { Over the past month, I have } \\
\text { developed a greater appreciation for } \\
\text { the arts (in the form of buildings, } \\
\text { paintings, literary works, etc.). } \\
\text { I read an article, watched a TV show, }\end{array}$ & 3.73 & 3.87 & 4.07 & 0.13 & 0.75 & 0.20 & 1.24 & 0.33 & 1.72 \\
\hline $\begin{array}{l}\text { or spoke to someone about how } \\
\text { Americans are viewed by people from } \\
\text { other countries. }\end{array}$ & 2.70 & 2.70 & 3.00 & 0.00 & 0.00 & 0.30 & 1.80 & 0.30 & 1.66 \\
\hline $\begin{array}{l}\text { I watched a non-American TV station, } \\
\text { news broadcast, or television show. } \\
\text { I have consciously withheld judgment }\end{array}$ & 2.63 & 2.47 & 2.57 & $0 . \overline{17}$ & -1.04 & 0.10 & 0.46 & $0 . \overline{0}$ & -0.30 \\
\hline $\begin{array}{l}\text { on a controversial international event } \\
\text { until I learned more facts. }\end{array}$ & 3.37 & 3.53 & 3.53 & 0.17 & 0.96 & 0.00 & 0.00 & 0.17 & 1.04 \\
\hline $\begin{array}{l}\text { I thought about the differences } \\
\text { between myself and people from other } \\
\text { countries. }\end{array}$ & 4.03 & 3.67 & 3.87 & $0 . \overline{37}$ & $-2.16^{\star}$ & 0.20 & 0.95 & $\overline{-} \overline{17}$ & -0.93 \\
\hline $\begin{array}{l}\text { I looked up something on a map of } \\
\text { another country. }\end{array}$ & 3.17 & 2.90 & 3.17 & $\begin{array}{c}- \\
0.27\end{array}$ & $-2.11^{\star}$ & 0.27 & 1.39 & 0.00 & 0.00 \\
\hline $\begin{array}{l}\text { I thought about the similarities } \\
\text { between myself and people from other } \\
\text { countries. }\end{array}$ & 3.37 & 3.30 & 3.67 & $0 . \overline{0}$ & -0.44 & 0.37 & 1.58 & 0.30 & 1.51 \\
\hline $\begin{array}{l}\text { I looked up a non-English word in a } \\
\text { dictionary. }\end{array}$ & 3.07 & 2.93 & 2.67 & $-\overline{13}$ & -0.60 & $0 . \overline{27}$ & -1.03 & $0 . \overline{40}$ & -1.72 \\
\hline $\begin{array}{l}\text { I thought about a current issue that's } \\
\text { important to the people of a } \\
\text { developing country. }\end{array}$ & 3.30 & 3.27 & 3.37 & $\overline{0 .}$ & -0.18 & 0.10 & 0.52 & 0.07 & 0.37 \\
\hline $\begin{array}{l}\text { I have listened to music sung in a } \\
\text { language other than English. }\end{array}$ & 2.97 & 3.13 & 3.07 & 0.17 & 0.76 & 0.07 & -0.28 & 0.10 & 0.50 \\
\hline
\end{tabular}

${ }^{\star \star *} p<.001 ;{ }^{* \star} p<.01 ; p<.05$ 